\title{
NARRATIVAS MITOLÓGICAS: SOB O OLHAR DA SEMIÓTICA GREIMASIANA
}

Tiago Souza Monteiro De Andrade

Universidade Estadual de Londrina - UEL. E-mail: tygerstone@ig.com.br

\section{RESUMO}

As origens de lendas povoadas por deuses e mortais perdem-se na memória do tempo. Essas lendas surgiram de forma espontânea, da imaginação popular, quando os registros da linguagem verbal eram muito diferentes da escrita de hoje. O conhecimento era passado oralmente através de gerações, por isso a matriz necessariamente da mitologia. Se hoje não precisamos mais dos mitos para responder às questões elucidadas pela precisão científica, eles ainda são fontes para pesquisas e para conhecer o percurso do pensamento humano. Nesse sentido, narrativas mitológicas são exemplos ricos de textos que podem ser estudados e neles aplicados metodologias científicas diversas. Por meio do instrumental teórico greimasiano, este artigo propõe uma análise estrutural da narrativa mitológica Orfeu e Eurídice, através do percurso gerativo de sentido definido em três níveis: narrativo, fundamental e discursivo.

Palavras-chave: semiótica, percurso gerativo de sentido, narrativas mitológicas.

\section{INTRODUÇÃO}

Aquilo que hoje conhecemos por mitologia greco-romana começou como históricas mágicas e alegóricas que os antigos inventaram para, na falta da ciência, responder a algumas perguntas: Como começou o Universo? Como surgiram os homens? O que há no além-mar? Para onde vão as pessoas quando morrem? O que faz um homem se apaixonar por uma mulher e viceversa? De onde surgiram os animais que habitam a terra? As respostas para essas e outras questões foram sendo forjadas pela sabedoria popular, isto é, não foram realizadas por autor específico, mas nasceram espontânea e anonimamente da necessidade delas próprias e passaram de geração em geração em relatos flexíveis, que modificaram e se modificam conforme as circunstâncias. De tempos em tempos, um compilador decide fixá-las na forma que melhor lhe convém, por isso que hoje se podem encontrar tantas versões de cada mito. Se hoje não precisamos mais dos mitos para responder às questões elucidadas pela precisão científica, eles ainda são fontes para pesquisas e para conhecer o percurso do pensamento humano. Nesse sentido, narrativas mitológicas são exemplos ricos de textos que podem ser estudados e neles aplicados metodologias científicas diversas, justificando sua importância. O corpus a ser estudado corresponde à narrativa mitológica Orfeu e Eurídice, de modo que este artigo objetiva analisar semioticamente o texto em questão, para observar e compreender como funcionam os mecanismos de produção (enunciação) de sentido do texto, por meio dos diferentes níveis de 
estruturação que compõem o percurso gerativo de sentido da significação, proposto por A. J. Greimas. A seguir é realizado um resgate teórico, seguido do corpus e análise deste e, finalmente, as considerações acerca do estudo.

\section{RESGATE TEÓRICO}

Para abordar a teoria semiótica, aplicada na narrativa mitológica em estudo, julga-se necessário deixar clara a definição de texto entendida neste trabalho. Nesse sentido, texto definese como objeto de significação, podendo ser tomado como sinônimo de discurso. Desse modo, propôs-se examinar os procedimentos e os mecanismos que o estruturam como um todo de sentido, sendo, portanto, a análise interna ou estrutural do texto. Para construir o sentido do texto, a Semiótica procura explicar o seu plano de conteúdo sob a forma de um percurso gerativo de sentido. O texto será examinado utilizando a metalinguagem específica proposta por Greimas para analisar e descrever a significação, apresentando as estruturas que compõem o conteúdo e segmentando-as em seus patamares ou níveis de significação. A essas estruturas Greimas denominou percurso gerativo de sentido.

O percurso gerativo de sentido é uma sucessão de patamares, cada um dos quais suscetível de receber uma descrição adequada, que mostra como se produz e se interpreta o sentido, num processo que vai do mais simples ao mais complexo. (...) Os três níveis do percurso são o profundo (ou fundamental), o narrativo e o discursivo. (FIORIN, 2008, p. 20)

Vejamos o esquema do percurso gerativo de sentido apresentado no quadro a seguir:

\begin{tabular}{|c|c|c|c|}
\hline \multicolumn{2}{|c|}{} & $\begin{array}{c}\text { Componente } \\
\text { Sintático }\end{array}$ & $\begin{array}{c}\text { Componente } \\
\text { Semântico }\end{array}$ \\
\hline \multirow{2}{*}{$\begin{array}{c}\text { Estruturas } \\
\text { Sêmio-narrativas }\end{array}$} & Nível & $\begin{array}{c}\text { Sintaxe } \\
\text { Fundamental }\end{array}$ & $\begin{array}{c}\text { Semântica } \\
\text { Fundamental }\end{array}$ \\
\cline { 2 - 4 } & Profundo & Sintaxe & Semântica \\
Nuperfície & Narrativa & Nartiva \\
\hline Estruturas & \multicolumn{2}{|c|}{ Sintaxe Discursiva } & $\begin{array}{c}\text { Semântica Discursiva } \\
\text { Tematização }\end{array}$ \\
Discursivas & \multicolumn{2}{|c|}{ Discursivização (actorialização, } & Figurativização \\
\hline
\end{tabular}

Fonte: FIORIN, J. L. Elementos de análise do discurso. 14. ed. São Paulo: Contexto, 2008, p. 20.

Para esclarecer melhor o percurso gerativo de sentido, deve-se considerar a sua composição, que são as estruturas sêmio-narrativas, constituindo o nível mais abstrato, instância do percurso gerativo de sentido e base da teoria que é instrumental para a análise, que, por sua vez, comporta dois componentes: os sintáticos e os semânticos. Estes comportam, por 
conseguinte, dois níveis de profundidade: a sintaxe e a semântica fundamentais (nível profundo); a sintaxe e a semântica narrativas (nível de superfície). E o nível das estruturas discursivas, composto também por um componente sintático e outro semântico.

Quanto ao primeiro, nível fundamental, corresponde ao momento em que se depreende a significação como uma oposição semântica mínima, a partir da qual se constrói o sentido do texto, em que se nega uma idéia para afirmar outra, isto é, essas relações são carregadas de valores axiológicos dados pelo texto. Todavia, a análise de um texto não consiste apenas em encontrar a oposição controladora dos seus sentidos, mas considera que nesta oposição reside uma unidade profunda figurativizada por elementos concretos que, à primeira vista, parecem dispersos.

Em relação ao segundo, nível narrativo, em que se organiza a narrativa, do ponto de vista de um sujeito e suas relações com o objeto. Neste caso, objeto não deve ser entendido como coisa, mas como tudo aquilo que um sujeito pode adquirir ou perder. Os objetos que os sujeitos podem perder ou adquirir subdividem-se em dois tipos: i) objetos modais (objetos necessários para adquirir outros objetos) que incluem o querer, o dever, o saber e o poder-fazer; e ii) o objetovalor (objetos que são a finalidade última a que visa o sujeito). Além disso, uma narrativa complexa estrutura-se numa sequência canônica, compreendida em quatro fases: a manipulação, a competência, a performance e a sanção.

Finalmente, o nível discursivo, que segundo Fiorin (2008, p. 41) "as formas abstratas do nível narrativo são revestidas de termos que lhes dão concretude"; além disso, "produz as variações de conteúdos narrativos invariantes". Neste último nível, predomina o maior grau de concretude (ou de maior complexidade) do texto e apresenta os aspectos de atores, tempo e espaço. "É a forma de um enunciado que por sua vez é produzido por uma enunciação" (PIETROFORTE, 2004, p. 19). No nível discursivo, os atores encontrados praticam ações no tempo e no espaço.

O estudo desses três níveis, enquanto diretrizes que norteiam a análise, facilitará o entendimento de como se produz e se interpreta o sentido do texto.

\section{CORPUS: buscando uma análise}

O texto selecionado para compor o corpus do presente trabalho se trata da narrativa mitológica intitulada - Orfeu e Eurídice. 


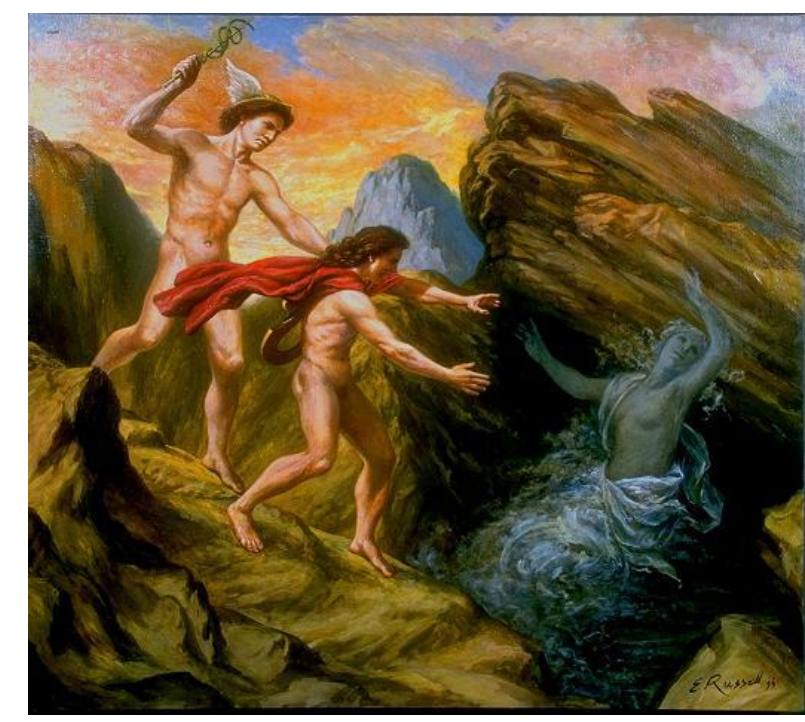

Orfeu e Eurídice - Gustave Moreau (1826 - 1898)

Óleo sobre Tela $-525 \mathrm{~cm} \times 473 \mathrm{~cm}$

PN1 Orfeu adorava a esposa Eurídice, uma ninfa. Recém-casado, a maior felicidade do filho de Apolo era tocar sua lira para a mulher. Sendo filho do deus da música, não era de estranhar, realmente, que tivesse a mesma perícia do pai. Por onde quer que Orfeu andasse, tocando o seu instrumento, tudo como que se paralisava, todos atentos, exclusivamente, ao som que saía de seus talentosos dedos.

- Toque outra canção para mim - pedia Eurídice todas as noites, antes de adormecer.

Era tanta paixão que a jovem nutria pela música do marido que às vezes o próprio Orfeu deixava de lado a lira, enciumado da própria música.

PN2 Um dia, Eurídice estava passeando com suas amigas ninfas quando, separando-se delas, entrou por vereda do bosque, onde gostava de caminhar. Sentado, com as costas apoiadas a um tronco, estava o pastor Aristeu, entregue aos seus pensamentos. Percebendo que alguém se aproximava, ergueu a cabeça.

- É ela, Eurídice! - disse Aristeu, que era apaixonado pela ninfa.

Levantando com rapidez, foi na direção da moça, tentando parecer que era um encontro casual. Eurídice, no entanto, recuou alguns passos ao vê-lo, pois sabia dos sentimentos que o pastor nutria por ela.

- Espere, volte aqui! - gritou Aristeu. - Não precisa se assustar.

Mas Eurídice não queria conversa. Por isso mesmo apertou mais o passo. Aristeu, revoltado, lançou-se em seu encalço. 
- Não adianta fugir de mim, Eurídice, pois a amo e ninguém me impedirá de tê-la um dia só para mim!

- Ninguém, a não ser minha vontade! - respondeu Eurídice.

Aristeu não escutou estas palavras, pois o amor só escuta o que lhe convém. Aproveitando que a mulher parara para lhe dizer estas palavras, agarrou os ombros dela e tentou beijá-la à força.

- Adoro você, Eurídice, e você ainda há de ser minha, de qualquer jeito! - exclamou o pastor com a voz alterada e o rosto congesto.

A ninfa, percebendo que corria perigo, arremessou-se numa corrida para dentro da mata. Enquanto fugia, sentia atrás de si os passos ligeiros de seu perseguidor. De repente, porém, Eurídice, aproximou-se perigosamente de uma serpente, que, assustada, acabou picando seu tornozelo. A ninfa caiu ao solo, com um grito de dor. Aristeu logo a alcançou, mas descobriu que nada mais podia fazer para salvar a sua amada. A jovem, aos poucos, perdia a consciência, ingressando no mundo das sombras.

PN3 Quando Orfeu recebeu a terrível notícia, sua alma cobriu-se de luto; sua lira, que até então somente tocara acordes alegres, agora silenciara; a partir daí, nas raras vezes em que tocava, tudo o que se ouvia eram sons tristes como um lamento. Não conseguindo mais viver sem sua adorada Eurídice, Orfeu tomou uma decisão extrema: foi até Júpiter, pedir que a trouxesse de volta da mansão dos mortos.

- Não posso fazer nada sem a concordância de Plutão - disse o pai dos deuses, convencido da dor do infeliz amante. - Tudo o que posso fazer é Ihe ceder Mercúrio, que o conduzirá até o reino do meu irmão.

- Ótimo! - disse Orfeu. - Irei amanhã mesmo até o inferno para trazê-la de volta.

PN4 Abandonando tudo, Orfeu partiu na outra manhã, tendo apenas a companhia de Mercúrio. Pela primeira vez desde a morte da esposa, o poeta mostrava-se um pouco animado, chegando até a tirar alguns alegres acordes de seu instrumento. Porém, logo retornou à sua música plangente, ao chegar à gruta que, segundo a tradição, dava acesso à morada dos mortos.

- Aqui é a entrada dos infernos - disse Mercúrio, apontando a cratera com seu caduceu.

Sem medo algum, Orfeu começou a descer as profundezas do terrível abismo. Quanto mais descia, maior era a escuridão, tanto que foi obrigado a ascender um facho. Depois de muito andar, avistou ao longe o brilho de algo tremeluzindo no chão. Era o Estige, um dos rios infernais que 
levam ao reino de Plutão. Ali estava ancorada uma barca, tendo ao lado e em pé Caronte, com sua longa barba branca e seu olhar de poucos amigos.

- O que quer aqui? - disse o velho, apalpando o visitante. - Você não tem aparência de um morto.

- Quero rever a minha esposa, que desceu recentemente a este lugar - disse Orfeu, com decisão. - Aqui está Mercúrio, que traz autorização do próprio Júpiter.

- E como pensa que vai passar para a outra margem? Com seu corpo pesado irá levar a pique a minha barca - disse Caronte, ameaçando o intruso com seu pesado remo.

- Vamos, toque logo esta droga! - ordenou Orfeu, sem se impressionar com as ameaças do velho senil. - Eu a manterei flutuando com os acordes de minha lira.

Intimidado com a vontade de Orfeu, Caronte desatou as amarras que prendiam a barca à terra e, maravilha para seus cansados olhos, ela flutuou com mais leveza do que nunca sobre as águas escuras do temível rio. Ao desembarcar, Orfeu acalmou com seu acordes a ira de Cérbero o monstruoso cão de três cabeças que guarda a entrada do inferno -, de modo que ele veio rastejando docilmente e lambeu com suas três línguas os pés do inesperado visitante. Depois Orfeu cruzou com vários condenados, que ao escutarem a melodia que saía das mãos do músico cessaram por alguns momentos a sua faina. As danaides deixaram cair ao chão os seus baldes de chumbo; Íxion deixou de girar a sua roda; e Sísifo abandonou o seu rochedo, que rolou colina abaixo.

PN5 Avançando sempre, Orfeu chegou, enfim, diante do trono de Plutão e de sua esposa, Prosérpina. Ambos pareciam interessadíssimos naquele vivo que chegava ao seu reino daquela maneira surpreendente.

- O que deseja aqui, visitante? - disse Plutão, brandindo seu tridente, como a demonstrar que, ainda que apreciasse a música, não aprovava aquela invasão de seus domínios.

- Vim implorar a vocês, soberanos do mundo subterrâneo, que peçam as Parcas para que reatem o fio partido da vida de minha esposa Eurídice, devolvendo-a a vida. Se não puderem ou não quiserem fazê-lo, no entanto, que cortem também o fio de minha vida, permitindo que eu permaneça junto a ela.

Impressionado com a retórica e com a melodia de Orfeu, Plutão pediu a Mercúrio que trouxesse a esposa do visitante. Impossível descrever a reação que se apoderou de Orfeu quando viu novamente a sua amada. Suas pernas tremiam; sua face convulsa era uma máscara de todos os rostos que a emoção podia pintar; e sua voz, um grito como jamais se ouviu igual. 
- Eurídice, você está viva! - disse o esposo à mulher morta.

Ela lançou-se aos braços de Orfeu e durante alguns minutos o inferno inteiro silenciou, em respeito à dor dos dois amantes.

- Esta bem, permito que você a leve de volta para a Terra - disse Plutão, com a concordância de Prosérpina. - Porém há uma condição.

- Sim, diga qual é - disse o impaciente Orfeu.

- Você deverá fazer o restante do trajeto sempre a frente de sua esposa, jamais voltandose para trás para olhar para ela. Se o fizer, imediatamente a perderá para sempre - disse o deus infernal, de maneira categórica.

- Está bem, assim o farei - disse Orfeu, seguindo adiante, levando atrás de si Eurídice e Mercúrio.

Refizeram, assim, todo o trajeto da descida, só que em sentido contrário. Por várias vezes Orfeu teve ímpetos de voltar-se para trás para ver se sua esposa ainda o acompanhava, recebendo sempre sua admoestação:

- Não, Orfeu, não se vire!

O poeta já divisava nas alturas a cratera por onde ele e o deus mensageiro haviam entrado. PN6 - Veja, Eurídice, estamos quase chegando! - disse Orfeu, voltando-se inadvertidamente para ela, a um passo da liberdade.

Nem bem seus olhos fixaram o rosto de sua amada, viu-a ser carregada de volta à escuridão pelos braços de Mercúrio.

- Espere, não, volte! - clamou Orfeu, devorando com os olhos a última imagem de Eurídice, que, com os olhos esgazeados, lhe estendia inutilmente as mãos.

Um grande terremoto sacudiu a caverna, fazendo com que um imenso rochedo bloqueasse para sempre o seu regresso ao reino das sombras. Orfeu, no último limite do desespero, arrancava os cabelos e dilacerava o rosto.

- Ai de mim! Por que fui olhar para trás no último minuto, faltando tão pouco! - dizia, inconsolado.

Mas nada mais havia de fazer. Eurídice estava longe dele, para sempre.

PN7 Orfeu, tal como o desgraçado Édipo, parecia destinado a ser perseguido incessantemente pelos deuses, até sua morte. Deixando o lugar, percorreu várias terras, arrancando se sua lira acordes lúgubres e ao mesmo tempo de uma beleza triste. Instalando-se numa floresta, na Trácia, Orfeu dedicou-se a tocar sua música, alheio a tudo o mais. As mulheres de lá, no entanto, não 
cessavam de persegui-lo em especial um grupo de bacantes - sacerdotisas de Baco -, que tudo faziam para conquistar seu amor. Era em vão que prometiam ao poeta raros prazeres e lhe diziam palavras das mais doces. Ele mostrava-se sempre irredutível, até que um dia, tomadas por um furor maligno, as mulheres avançaram para ele, lançando-lhe pedras e dardos, sem, no entanto, atingi-lo, pois sua música o protegia.

- Abafem o som da música! - disse uma das bacantes, enlouquecida de ódio.

Batendo seus tambores e estalando seus címbalos, elas finalmente conseguiram abafar a música de Orfeu, tornando-o vulnerável aos seus ataques. Uma chuva de pedras e dardos desceu, então, sobre o poeta, que tombou morto sob este implacável ataque. Não satisfeitas, as bacantes ainda pegaram o corpo do músico e o fizeram em pedaços, lançando sua cabeça e sua lira no rio que levava o mesmo nome do poeta. Enquanto elas avançavam juntas em direção ao mar, iam passando pelas margens, encantando os pastores e as ninfas que as habitavam. A alma de Orfeu, no entanto, estava liberta, e tão logo se viu livre de suas perversas algozes, o poeta correu para os braços de sua Eurídice, que o aguardava no mesmo lugar onde ele a deixara.

\section{ANÁLISE DO TEXTO}

O presente estudo objetiva indicar como se articulam diferentes níveis de formulação que levam ao estabelecimento da narratividade e a sua ligação com a estrutura elementar da significação. Vejamos a análise sob os três níveis de estruturação:

\section{- Nível Fundamental}

As estruturas fundamentais, conforme propõe a teoria semiótica, "é a primeira etapa do percurso de geração do sentido de um discurso." (BARROS, 1998, p. 9).

Segundo Fiorin (2008, p.21) "A Semântica do nível fundamental abriga as categorias semânticas que estão na base de construção de um texto". No texto em estudo, as categorias do nível fundamental são /vida/ versus /morte/. Além disso, deve-se considerar as categorias semântica e fórica que estão na base da construção de um texto. A categoria fórica é projetada sobre a semântica sendo que a euforia caracteriza um valor positivo e a disforia um valor negativo. Portanto, a projeção das categorias fóricas dá-se segundo o ponto de vista de um sujeito. Em Orfeu e Eurídice, a morte é considerada um termo eufórico, isso porque era o único meio para que Orfeu ficasse para sempre ao lado de sua amada Eurídice. A escolha da categoria semântica deve ser adequada de modo a permitir uma sistematização dos valores, isto é, a relação entre dois termos contrários. 
Os termos opostos de uma categoria semântica mantêm entre si uma relação de contrariedade, elementos que se encontram no quadrado semiótico que

(...) situa-se na semântica fundamental, ponto de partida do processo generativo. Este consiste na trajectória de produção do objecto semiótico, das estruturas profundas às estruturas de superfície, do mais simples ao mais complexo, do mais abstracto ao mais concreto. (FIDALGO \& GRADIM, 2005, p. 127).

Desse modo, o quadrado semiótico de Greimas realiza a sintaxe das relações sistematizadas. Pode-se representá-las e visualizá-las, traduzindo suas relações em oposições de contradição, contrariedade e complementaridade. As categorias /vida/ e /morte/ mantêm entre uma relação de oposição, sendo declarados termos contrários.

O quadrado semiótico para essas duas categorias mostra-se da seguinte forma:

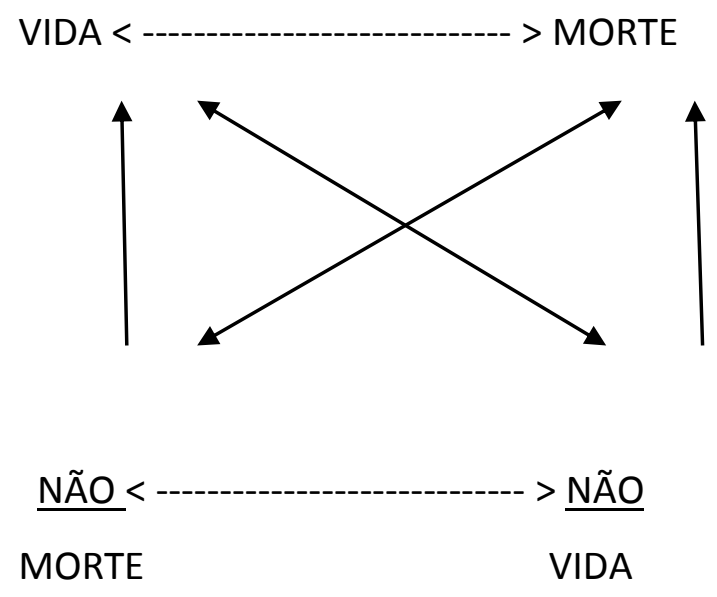

Nesse esquema, encontramos quatro tipos de relações:

- de oposição ou contrária, relativa à categoria semântica de partida (vida -- morte);

- de negação lógica ou contraditória, que se desenvolve ao longo das diagonais (vida -- nãovida e morte -- não-morte);

- a partir da contraditória, obtemos a subcontrária, que vemos no eixo horizontal inferior (não-vida -- não-morte);

- finalmente, observamos a deixis ou implicação nos lados verticais (vida -- não-morte e morte -- não-vida).

\section{- Nível Narrativo}

Segundo Greimas (1979, p. 352) o programa narrativo (doravante PN), "é um sintagma elementar da sintaxe narrativa da superfície, constituído de um enunciado de fazer que rege um enunciado de estado". A narrativa mínima se baseia na transformação de um estado de coisas, 
pela privação ou aquisição, que resultam de uma ação. Para compreender esse mecanismo de transformação, é necessário considerar dois tipos opostos de enunciado de estado definidores da relação que o sujeito mantém com os objetos: ou ele está em posse das qualidades e dos valores inscritos nesses objetos ou não. O conceito semiótico de junção define essa relação elementar por meio dos termos: conjunção e disjunção. Este corresponde quando o sujeito está disjunto (privado) do seu objeto-valor. Já aquele corresponde quando o sujeito está conjunto (possui) o objeto-valor.

Dessa forma, o PN é uma função (um fazer) pela qual um sujeito de fazer faz com que um sujeito de estado se torne disjunto de um objeto ao qual estava conjunto, ou vice-versa.

O PN se apresenta como uma fórmula elementar que as estruturas das narrativas se desenvolvem, complexificam e hierarquizam distintamente. Podemos, desse modo, distinguir as narrativas de aquisição de valores e as narrativas de perda de valores. Ademais, de acordo com Fiorin (2008, p. 29) os textos não são narrativas mínimas, mas sim complexas, de modo que uma série de enunciados de fazer e de ser estão organizados hierarquicamente. No texto em análise, podemos observar uma serie de desdobramentos dentro do texto como um todo. A estrutura tradicional de uma narrativa complexa apresenta-se com as seguintes fases em sua composição: i) manipulação, ii) competência, iii) performance e iv) sanção.

$\mathrm{Na}$ fase de manipulação, um sujeito age sobre o outro para levá-lo a querer e/ou dever fazer algo. Na fase de competência, o sujeito que vai realizar a transformação central da narrativa é dotado de um saber e/ou poder fazer. Na fase performance, trata-se do momento em que se dá a transformação, ou seja, a mudança de um estado para outro na narrativa. Finalmente, na fase de sanção, ocorre a averiguação de que a performance foi realizada e o reconhecimento do sujeito que operou a transformação, seja algo positivo seja algo negativo.

Barros (1998, p. 26) acrescenta um conceito pertinente sobre o percurso narrativo. Segundo a autora, trata-se de uma sequência de programas narrativos relacionados por pressuposição. Tal percurso é constituído pelo encadeamento lógico de programas de competência com programas de performance.

Na narrativa em análise, corpus do trabalho, são apresentados os possíveis programas narrativos (PNs) que buscam a significação do texto na frente da cada parágrafo. Iniciemos, assim, a análise de cada um.

No PN1, inicialmente o sujeito Orfeu (sujeito de fazer e de estado), em conjunção com o objeto-valor (Eurídice), sabia, queria e podia mantê-la em seus braços. Além disso, por ser filho do 
deus da música, tinha em mãos um instrumento que encantava tanto sua amada como a quem a ouvia, temos um PN de competência realizado.

No PN2, Eurídice, ninfa esposa de Orfeu é perseguida por um admirador, Aristeu, durante um passeio na floresta. Ela quer e deve, mas não possui meios para impedir a insistência do admirador. Todavia, ela sabe e pode correr dele, para não ser pega. Ao ser picada por uma serpente, o sujeito Eurídice entra em disjunção com a vida.

No PN3, Orfeu tem conhecimento da notícia da morte de sua esposa. Nesse sentido, ele entra em disjunção do objeto-valor Eurídice. Ele quer, mas não pode trazê-la de volta do mundo das sombras. Todavia, Orfeu é o sujeito do saber, pois sabe como pode trazê-la de volta, manipulando Júpiter, através de um pedido, e levando-o a dever fazer. Júpiter faz Mercúrio acompanhar Orfeu até o inferno em busca do objeto-valor. Temos um PN de competência realizado.

No PN4, com o contrato firmado no PN3, Orfeu com o auxílio de Mercúrio é o sujeito do saber-fazer, do poder-fazer e do querer-fazer. Isso porque tem a competência, através de seu instrumento musical (lira), de ultrapassar todos os obstáculos previstos até o encontro com Plutão, deus dos infernos. Com o som de sua lira, fez a barca de Caronte flutuar, a ira de Cérbero desaparecer e a faina dos condenados cessar. Desse modo, o PN de competência e performance realizado.

No PN5, com o PN4 de competência realizado, Orfeu chega até Plutão, para implorar o retorno de sua amada ao mundo dos vivos. Para isso, manipula o deus dos mortos através por sedução "soberano do mundo subterrâneo", levando a firmar o contrato por meio de sua retórica e de sua melodia. No entanto, com o contrato fechado, Orfeu tinha uma condição: não olhar para trás no trajeto de volta ao mundo dos vivos, sob a punição de perder o objeto-valor. Nesse PN, Orfeu entra em conjunção com seu objeto-valor, após sua performance, sendo sancionado positivamente com o retorno de sua amada.

No PN6, Orfeu descumpre o contrato, olhando para trás, e entra em disjunção com seu objeto-valor. Dessa forma, é sancionado negativamente e o PN de competência não é realizado.

No PN7, finalmente, apesar do PN de competência anterior não ter sido realizado, visto que houve a quebra de contrato estabelecido no PN5, Orfeu ainda tocava alguns tristes acordes. Desiludido, apesar querer, mas não saber e poder trazer sua esposa de volta entra em lamentações. Consequentemente, as bacantes, vendo-o nessa situação, tentam conquistar o seu amor, mas sem sucesso pela irredutibilidade do pobre poeta. Após uma serie de insistências, 
abafam o som de sua lira, sua proteção, e matam-no com chuva de pedras e dardos. Nesse último PN, Orfeu entra em disjunção com a vida, porém em conjunção com seu objeto-valor, Eurídice, a qual se encontrava a sua espera no mundo das sombras. Tendo, por sua vez, uma sanção positiva.

- Nível Discursivo

É no nível discursivo que as formas abstratas são especificadas e concretizadas e o primeiro passo é fazer com que os arranjos modais do nível narrativo sejam espacializados, temporalizados e actorializados. Este nível também apresenta um componente sintático e um semântico.

$\mathrm{Na}$ análise semiótica, o sentido do texto se constrói sob a forma de um percurso gerativo, em que o nível discursivo é o patamar mais superficial do percurso, o mais próximo da manifestação textual.

O nível discursivo é o plano de conteúdo do texto resultado da conversão das estruturas sêmio-narrativas em estruturas discursivas pelo sujeito da enunciação.

A sintaxe narrativa apresenta os seguintes elementos: efeito de imparcialidade, efeito de realidade e conhecimentos compartilhados.

Para criar a sensação de imparcialidade, o narrador narra em 3a pessoa os PNs, o que aumenta a credibilidade do texto, porque o narratário está acostumado a ser conduzido por um observador que, às vezes, passa a voz aos interlocutores. Além disso, em alguns desses PNs, como PN4, PN5 e PN6, há a passagem em demasia da fala das personagens, ou seja, o discurso direto. Quanto aos conhecimentos compartilhados, pode-se dizer que: i) Orfeu ama Eurídice, ii) Orfeu tem propriedade em tocar a lira, iii) o som da lira encantava a todos, iv) Orfeu não podia ir sozinho ao inferno, v) Plutão é deus do inferno e não há outro que lá dê as ordens e vi) as pessoas quando morrem vão para o inferno.

Em relação à semântica narrativa, "os valores assumidos pelo sujeito da narrativa são, no nível discursivo, disseminados sob a forma de percursos temáticos e recebem revestimentos figurativos." (BARROS, 1994, p. 68).

Ao sujeito da enunciação, cabe a incumbência de disseminar os temas a figurativização deles. Nesse sentido, a oposição entre tem e figura nos remete à oposição abstrato/concreto.

Os procedimentos semânticos do discurso são, desse modo, a tematização e a figurativização.

Segundo Barros (1998, p.90) "tematizar é um procedimento semântico do discurso que consiste na formulação abstrata de valores narrativos e na sua disseminação em percursos, por meio da recorrência de traços semânticos". 
A figurativização, ainda segundo Barros (1988, p. 87), "é o procedimento semântico pelo qual conteúdos mais concretos (que remetem ao mundo real) recobrem os percursos temáticos abstratos".

Nesse componente semântico do discurso, o sujeito que luta por resgatar sua amada das profundezas do inferno, falha nessa busca e se mantém irredutível ao amor de outras até a morte pode converter-se nos seguintes percursos temáticos: i) o amor verdadeiro vale a pena, ii) existe fidelidade e a lealdade quando se ama, iii) quem ama se doa e iv) o amor continua após a morte.

Trata-se de um discurso com percurso figurativo duradouro, já que a figurativização ocorre no discurso inteiro e recobre totalmente o discurso temático.

\section{CONSIDERAÇÕES FINAIS}

A conclusão que se chega desta análise não é definitiva nem engessada, por permitir outras leituras e releituras referentes ao percurso gerativo de sentido. Observamos que a narrativa desenvolvida pelo texto analisado é ordenada por um conjunto de encadeamento lógico, onde os sujeitos percorrem diferentes performances na busca de seus objetos-valores.

Ressalta-se que o texto permite várias interpretações, ou seja, é possível perceber vários programas narrativos diante de uma mesma situação. Para esta análise ficamos restritos nesses sete programas narrativos, sendo, um de base, cinco do sujeito Orfeu e um do sujeito Eurídice. Entende-se assim, que estes sete programas narrativos representam as características e as performances mais evidentes na narrativa mitológica Orfeu e Eurídice.

\section{REFERÊNCIAS BIBLIOGRÁFICAS}

ANDRADE, Tiago Souza Monteiro de. Um estudo sobre os tempos verbais em narrativas mitológicas. 2009. 61 f. (Especialização em Língua Portuguesa). UNESP - Universidade Estadual Paulista - Faculdade de Ciências e Letras, Assis-SP.

BARROS, Diana Luz Pessoa de. Teoria do discurso: fundamentos semióticos. São Paulo: Atual, 1998. . Teoria semiótica do texto. São Paulo: Ática, 1994.

FIDALGO, António \& GRADIM, Anabela. Manual de semiótica. Disponível em: http://pt.scribd.com/doc/52782963/32/O-quadrado-semiotico-de-Greimas. Acesso em: 13 de jul de 2012.

FIORIN, José Luiz (org.). Introdução à linguística: objetos teóricos. 5. ed. São Paulo: Contexto, 2006. 
FIORIN, José Luiz. Elementos de análise do discurso. 14. ed. São Paulo: Contexto, 2008. . Linguagem e ideologia. 8.ed. São Paulo: Ática, 2006. (série princípios).

FRANCHINI, A. S. \& SEGANFREDO, Carmem .As 100 melhores histórias da mitologia:_Deuses, heróis, monstros e guerras da tradição greco-romana. 6. ed. Porto Alegre: L\&PM, 2004. p.152-155.

GREIMAS, Algirdas Julien \& COURTES, Joseph. Dicionário de semiótica. São Paulo: Cultrix, 1979.

PIETROFORTE, Antonio. Semiótica Visual: os percursos do olhar. São Paulo: Contexto, 2004. 